\title{
Identificación molecular de Candida lusitaniae en infección de tracto respiratorio inferior
}

\author{
(Molecular identification of Candida lusitaniae in lower respiratory tract infection)
}

\author{
1'Martínez E Israel, ' 'González I Misael, 'Torres G Haydee*. \\ 1Laboratorio de Micología Básica, Unidad de Medicina Experimental, \\ Facultad de Medicina, UNAM, Dr. Balmis No.148, Col. Doctores, \\ Del. Cuauhtémoc, México DF. \\ 2Laboratorio de Inmunoalergología y Micología Médica, \\ División de Investigación. Hospital Juárez de México OPD. SSA. \\ * Autor para correspondencia: htorresguerrero@gmail.com
}

RECIBIDO: 30 de Julio de 2014

APROBADO: 06 de Octubre de 2014

LOS AUTORES DECLARAN NO TENER CONFLICTO DE INTERESES

Palabras clave: Candida lusitaniae, PCR-RFLP, candidosis profunda, infección de tracto respiratorio inferior, ITS, DNA ribosómico.

Key words: Candida lusitaniae, PCR-RFLP, lower respiratory tract infection, ITS, ribosomic DNA.

\section{RESUMEN}

Candida lusitaniae es una levadura que ha sido descrita como un patógeno nosocomial emergente de baja frecuencia en infecciones profundas. La identificación oportuna de $C$. Iusitaniae es importante porque puede desarrollar resistencia in vivo a la amfotericina B durante la terapia. Reportamos el aislamiento de $C$. Iusitaniae como agente etiológico de infección de tracto respiratorio inferior en un paciente masculino. Los cultivos de orina y esputo fueron negativos para bacterias y positivos para esta levadura. Los aislamientos fueron identificados por métodos fenotípicos de rutina y confirmados por secuenciación y polimorfismos de longitud de fragmentos de restricción y PCR de la región espaciadora interna del DNA ribosómico.

\section{INTRODUCCIÓN}

Las infecciones por levaduras del género Candida son las micosis más frecuentes. Estas forman parte de la microbiota de la cavidad oral y tracto

\section{ABSTRACT}

The yeast Candida lusitaniae has been described as an emerging low frequency nosocomial pathogen in deep infections. Early identification of $C$. Iusitaniae is important because it can readily develop in vivo resistance to amphotericin B during treatment. We report the isolation of $C$. Iusitaniae as etiologic agent of a lower respiratory tract infection in a male patient. Urine and sputum cultures were negative for bacteria and positive for yeast. Isolates were identified by routine phenotypic methods and confirmed by ribosomal DNA internal spacer region restriction fragment length polymorphism PCR and sequencing.

respiratorio superior en individuos sanos. Candida albicans es la principal especie comensal (69\% a $90 \%)$ y en menor frecuencia C. parapsilosis, C. tropicalis, C. krusei y C. glabrata (6). La distribución de las especies no albicans varía en función de la población y 
región geográfica (12). En condiciones de inmunosupresión y otros procesos debilitantes estás levaduras pueden comportarse como patógenos oportunistas y ocasionar infecciones profundas.

En las últimas décadas se ha reportado el aumento de candidosis profundas por especies noalbicans, principalmente candidemia e infecciones respiratorias asociadas a contaminación de catéteres venosos centrales, ventiladores mecánicos, uso crónico de antibióticos de amplio espectro y larga estancia intra hospitalaria. El diagnóstico de estas es complicado ya que requiere aislamiento del agente causal y el estudio histopatológico de biopsias de tracto respiratorio respectivamente. A continuación describimos un caso de infección de tracto respiratorio inferior refractario a tratamiento antimicrobiano, con aislamiento de $C$. Iusitaniae a partir de esputo y orina y respuesta a tratamiento antimicótico.

\section{Caso clínico}

Varón de 41 años proveniente del Estado de México. Trabajó en Texas colocando asfalto durante 2011, y refiere haber estado expuesto a solventes. Presenta desde hace dos años hipertensión arterial bajo tratamiento y sin padecimientos neoplásicos, autoinmunes 0 hematológicos. El padecimiento comenzó en agosto de 2012 con tos no productiva, disnea, dolor pleurítico, fiebre $\left(39^{\circ} \mathrm{C}\right)$, náuseas y pérdida importante de peso $(10 \mathrm{Kg})$.

Ingresó en septiembre de 2012 con diagnóstico de neumonía adquirida en la comunidad PORT I (día 1). La radiografía de tórax indicó parénquima pulmonar con patrón macronodular radio opaco parcheado en el $100 \%$ del hemitórax derecho con imágenes macronodulares en parénquima izquierdo de predominio basal. A la exploración se le encontró consciente, con palidez de tegumentos, no adenomegalias, amplexión y amplexación disminuidas en región basal izquierda, a la percusión claro pulmonar, auscultación con estertores subcrepitantes en región infraescapular bilateral de predominio izquierdo. El análisis hematológico índico un elevación de creatinina $(\mathrm{Cr}=2.5 \mathrm{mg} / \mathrm{dL})$, nitrógeno ureico sanguíneo (BUN=
$33.8 \mathrm{mg} / \mathrm{dL}$ ) y la relación $\mathrm{BUN} / \mathrm{Cr}=13.5$, indicaron una lesión renal aguda AKINII.

Se inició tratamiento con levofloxacino $750 \mathrm{mg} /$ $48 \mathrm{~h}$. Al día 2 continúa con picos febriles $\left(39^{\circ} \mathrm{C}\right)$ y con dolor pleurítico. Al día 3, presentó leve mejoría de la tos, sin dificultad respiratoria, se le realizaron micronebulizaciones con solución salina para favorecer la expectoración. Se envió esputo y sangre para la búsqueda de bacterias y baciloscopías. Se realizó el panel viral en búsqueda de VHB, VHC y VIH, no presentó reacción. La citometría hemática mostró leucocitosis. Presentó fiebre $\left(39^{\circ} \mathrm{C}\right)$ el día 3 y se cambió la terapia a ceftriaxona $1 \mathrm{~g} / 12 \mathrm{~h}$, claritromicina $500 \mathrm{mg} / 12 \mathrm{~h}$ y paracetamol. Al día 4 continúan los síntomas, se mantiene la leucocitosis, picos febriles y se presentó erupción maculopapular generalizada y rash asociado probablemente por alergia a claritromicina o paracetamol por lo que se suspenden ambos fármacos. Cultivos bacteriológicos y baciloscopías negativas. Al día 5 se envió esputo para búsqueda de hongos y muestras de sangre para cultivos bacterológicos y baciloscopías, se continuó la terapia con antibiótico. El paciente continuó con picos febriles $\left(39^{\circ} \mathrm{C}\right)$. Al día 6 en el esputo, se identificaron cúmulos de blastoconidios gemantes de 4 a $6 \mu \mathrm{m}(+++)$. Se inició terapia antifúngica con fluconazol $100 \mathrm{mg} / 12 \mathrm{~h}$ y se continuó el tratamiento antibacteriano.

A partir del esputo, se obtuvo desarrollo en agar de Sabouraud (colonias cremosas de 3 a $4 \mathrm{~mm}$, de color blanco, de bordes lisos) y en CHROMagar Candida ${ }^{\circledR}$ colonias similares pero de color rosado (Fig. 1). La asimilación de carbohidratos se realizó con el sistema API 20C aux y el perfil obtenido se comparó con la base de datos APIweb (https:// apiweb.biomerieux.com/), identificándose como $C$. Iusitaniae. Además, se determinó la sensibilidad a antifúngicos con FUNGITEST (BIORAD) y se reportó como sensible a amfotericina $\mathrm{B}\left(\mathrm{MIC}_{50}<2 \mu \mathrm{g} / \mathrm{mL}\right)$, 5-fluorocitosina ( $\mathrm{MIC}_{50}<2 \mu \mathrm{g} / \mathrm{mL}$ ), ketoconazol $\left(\mathrm{MIC}_{50}<0.5 \mu \mathrm{g} / \mathrm{mL}\right)$, fluconazol ( $\mathrm{MIC}_{50}<8 \mu \mathrm{g} / \mathrm{mL}$ ) y con resistencia intermedia a miconazol $\left(\mathrm{MIC}_{50}<8\right.$ $\mu \mathrm{g} / \mathrm{mL}$ ) e itraconazol $\left(\mathrm{MIC}_{50}<4 \mu \mathrm{g} / \mathrm{mL}\right)$ de acuerdo a las instrucciones del kit. 
Ante estos resultados se continuó con fluconazol $100 \mathrm{mg} / 12 \mathrm{~h}$. El día 7 se envió sangre y orina para búsqueda de hongos, se reportó presencia de blastoconidios (+) en esta última. Los días 7 al 9 el paciente presentó mejoría en movimientos de amplexión y amplexación, sin fiebre y el rash cutáneo en remisión con leve prurito al estímulo táctil. El día 9 se observó desarrollo solo en la muestra de orina, por tanto se envió sangre, esputo y orina para monitorear la infección. Para el día 11 los cultivos estaban negativos, valores hematológicos normales y el paciente no presentó complicaciones y se dio de alta.

Debido a que no se han reportado en el hospital casos de $C$. Iusitaniae y para descartar una posible identificación errónea, se realizó el análisis molecular (PCR- RFLP y secuenciación) del fragmento ITS1, ITS2 y $5.8 \mathrm{~S}$ rARN. Se utilizaron los primers universales ITS1 (5'-TCC GTA GGT GAA CCT GCG G-3') e ITS4 (5'-TCC TCC GCT TAT TGA TAT GC-3'). La PCR se realizó en un volumen final de $20 \mu \mathrm{L}$ conteniendo 30 ng de DNA muestra, $1 \mu \mathrm{M}$ de cada primer, $100 \mu \mathrm{M}$ de dNTP's, $2 \mu \mathrm{L}$ de $10 \mathrm{X}$ PCR buffer, $1.5 \mathrm{mM}$ de $\mathrm{MgCl}_{2}$ y $2.5 \mathrm{U}$ de Taq DNA polimerasa. El producto de amplificación se revisó por electroforesis en un gel de agarosa - bromuro de etidio al $2 \%$ dando una banda de 382 pb (Fig. 2A), posteriormente se incubó con $10 \mathrm{U}$ de $M s p /$ a $37^{\circ} \mathrm{C}$. La enzima digirió el fragmento en un solo sitio y generó dos fragmentos de DNA de 118 y 264 pb (Fig. 2B). La secuencia de la región ITS fue analizada utilizando BLAST de GenBank ${ }^{\circledR}$ y corresponde con un $100 \%$ de similitud con la secuencia del mismo locus de la cepa tipo C. Iusitaniae CBS 10625, nº de acceso EU149777.1).

\section{Discusión}

C. Iusitaniae está reconocida como patógeno oportunista nosocomial y es un organismo único por su habilidad de desarrollar rápidamente resistencia durante el tratamiento a agentes antifúngicos como anfotericina B y fluconazol $(3,4,5,9)$.A nivel mundial se reportan poco más de 50 casos de infecciones profundas en pacientes con linfomas, leucemia, cáncer y en recién nacidos $(1,2,7,11)$. En México, en los últimos 10 años solo se han reportado un caso de candidemia por C. Iusitaniae (10).

Nuestro reporte sugiere un caso de neumonía por C. Iusitaniae. Sin embargo, el diagnóstico definitivo requiere de la prueba histológica del tejido pulmonar con la presencia del microorganismo en asociación con la inflamación. La confirmación histopatológica no se realizó en este paciente debido a consideraciones éticas sin embargo, la notable mejoría clínica y de imágenes después de la iniciación del tratamiento antimicótico sistémico y el hecho de que no hay reportes que describan a $C$. lusitaniae como parte de la microbiota sugieren un diagnostico compatible con candidosis pulmonar.

El aislamiento únicamente de colonias de $C$. Iusitaniae a partir de la orina del paciente puede interpretarse como una probable diseminación hematológica a vías urinarias (facilitada por la lesión renal aguda), sin embargo no se pudo realizar el aislamiento a partir de sangre, ni un segundo aislamiento a partir de las otras muestras debido a la administración del antifúngico.

Es imprescindible la identificación oportuna de especies de no-albicans, principalmente en micosis profundas y en pacientes con factores de riesgo debido a que presentan diferentes susceptibilidades a los antifúngicos de primera línea. El estudio del genoma de diferentes levaduras ha contribuido al desarrollo de pruebas moleculares basadas en PCRRFLP y secuenciación de los ITS ribosomales que son sensibles, reproducibles y rápidas (8). Estas permiten establecer el diagnóstico clínico y la selección del tratamiento adecuado en pacientes con infecciones profundas.

\section{Agradecimientos}

El presente trabajo ha sido financiado por la Dirección General de Asuntos del Personal Académico (DGAPA) DGAPA-UNAM IN214013 


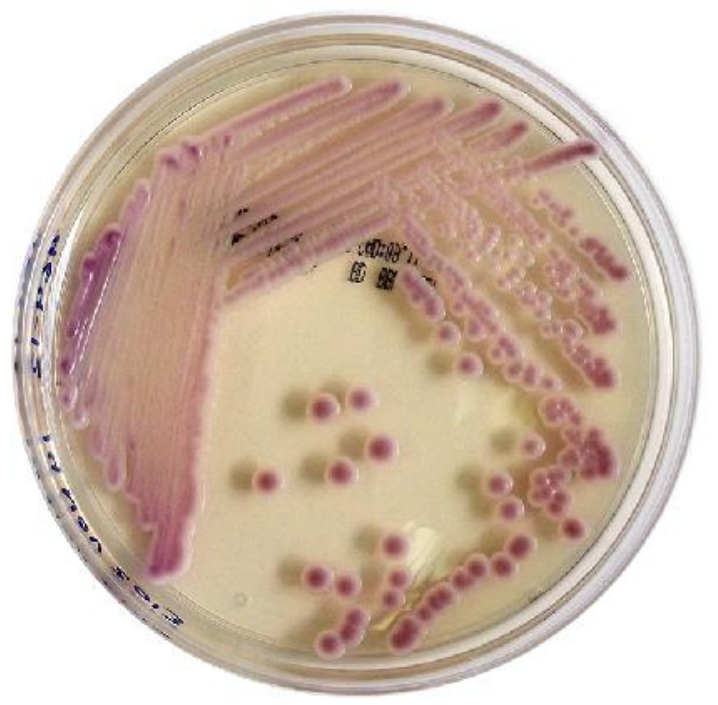

Figura 1. Colonias de C. Iusitaniae en CHROMagar Candida.
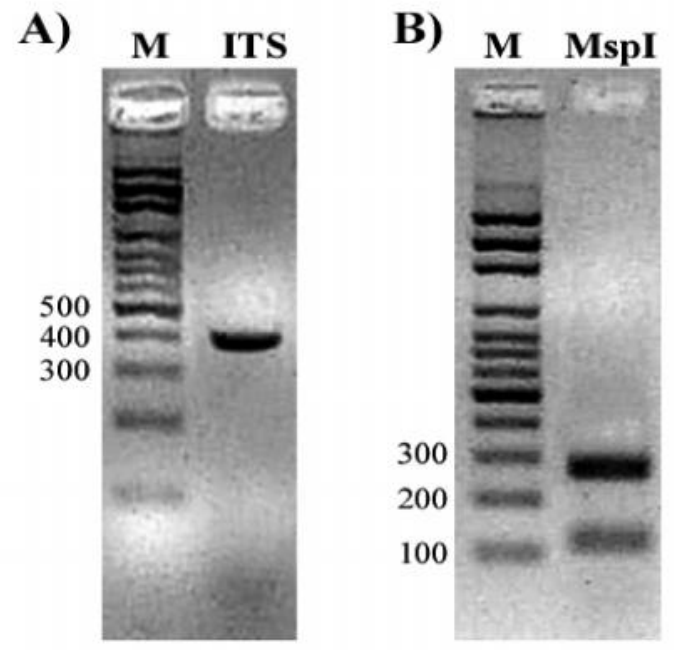

Figura 2. A) Gel de agarosa que muestra el producto amplificado (ITS1-5.8S-ITS4) de C. Iusitanie. (B) Fragmentos de restricción del producto de PCR con la enzima Mspl (RFLP). M: marcador de peso molecular, escalera de 100pb. (Patrón descrito por Mohammadi et al, 2013)

\section{REFERENCIAS}

1. Bariola J, Saccente M. Candida Iusitaniae septic arthritis: case report and review of the literature. Diagn Microbiol Infect Dis 2008; 61: 61-63

\section{Blinkhorn RJ, Adelhorn D, Spagnuolo PJ.} Emergence of a new opportunistic pathogen, Candida Iusitaniae. J Clin Microbiol 1989; 27:236-40.

3. Christenson JC, Guruswany A, Mukwaye G, Rettig PJ. Candida lusitaniae: an emerging human pathogen. Pediatr Infect Dis. 2007; 6:755-57

4. Favel A, Michel-Nguyen A, Peyron F, Martin C, Thomachot L, Datry A, BoucharaJ, et al. Colony morphology switching of Candida luisitaniae and acquisition of multidrug resistance during treatment of a renal infection in a newborn: case report and review of the literature. Diagn Microbiol Infect Dis 2003; 47: $331-39$

5. Hadfield TJ, Smith MB, Winn RE, Rinaldi MG,Ceuena C. Mycoses caused by Candida lusitaniae. Rev. Infect. Dis. 1987; 9:1006-12
6. Kleinegger CL, Lockhart SR, Vargas K, Soll DR. Frequency, intensity, species and strains of oral Candida vary as function of host age. J Clin Microbiol. 1996; 34 (9): 2246-54

7. Minari A, Hachem R, Raad I. Candida lusitaniae: A cause of Breakthrough Fungemia in Cancer Patients. Clin Infect Dis 2001; 32: 186-90

8. Mohammadi R, Mirhendi H, Makimura $\mathrm{K}$, et al. Molecular identification and distribution profile of Candida species isolated from Iranian patients. Med Mycol 2013; 51: 657-63

9. Pappagianis D, Collins $M$, Hector R, Remington J. Development of Resistance to Amphotericin B in Candida lusitaniae Infecting a Human. Antimicrob Agents Chemother 1979; 16 (2): 123-25

10. Reséndiz-Sánchez J, Morales-Aguirre J. Factores asociados a mortalidad por fungemias causadas por Candida sp. en niños. Boletín Médico del Hospital Infantil de México 2007; 64 (2): 91-98 
Identificación molecular de Candida lusitaniae en infección de tracto respiratorio inferior - I. Martinez et al

11. Sánchez V, Vázquez J, Barth-Joes D, Dembry L, 12. Xu J, Mitchell TG. Geographical Differences in Sobel J, Zervos M. Epidemiology of Nosocomial Human Oral Yeast Flore. Clin Infect Dis 2002; 36: 221Acquisition of Candida lusitaniae. J Clin Microbiol 1992; 24

30 (11): $3005-8$ 